\title{
Ganglion cyst in children: Reviewing treatment and recurrence rates
}

\author{
Tatiana Karine Simon Cypel MD MSc ${ }^{1 *}$, Amir Mrad MD ${ }^{1 *}$, \\ Gino Somers MBBS PhD 2,3 , Ronald Melvin Zuker MD FRCSC FACS ${ }^{1}$
}

TKS Cypel, A Mrad, G Somers, RM Zuker. Ganglion cyst in children: Reviewing treatment and recurrence rates. Can J Plast Surg 2011;19(2):53-55.

BACKGROUND: Pediatric hand and wrist ganglia seem to have different epidemiological characteristics than those of adults - a majority are found on the volar aspect of the hands and wrists of patients younger than 10 years of age.

OBJECTIVE: To determine the epidemiology, etiological factors, clinical presentation, treatment and outcome of patients with ganglion cysts at The Hospital for Sick Children (Toronto, Ontario).

METHODS: The records of the pathology department at The Hospital for Sick Children were searched for all cases of ganglion cyst operated on between January 2000 and December 2008.

RESULTS: Thirty-seven patients underwent treatment for symptomatic ganglion cyst. The mean age of the patients was 9.6 years, and there were 23 females. A mobile nodule was the initial presentation of the ganglion in $64 \%$ of the cases. Pain was the most common indication for surgical removal. Only $11.4 \%$ of patients experienced previous trauma. In $70 \%$ of the cases, the diagnosis was made clinically. The most common sites of occurrence were volar wrist $(25.7 \%)$, dorsal wrist $(22.8 \%)$ and the volar aspect of the base of the ring finger $(17.1 \%)$. Surgical excision was the treatment of choice for $94.2 \%$ of the patients with symptomatic lesions. The minimum follow-up period was 12 months. Only one patient $(2.8 \%)$ presented with recurrence in the series.

CONCLUSION: Although it is possible that these findings might change with longer follow-up, the present data provide information to help guide the treatment of these cysts. Complete surgical removal is a very effective treatment, with low rates of recurrence.

Key Words: Children; Ganglion cyst; Surgical treatment

\section{L'analyse du traitement et des taux de récurrence du kyste ganglionnaire chez l'enfant}

HISTORIQUE : Les ganglions de la main et du poignet dans la population pédiatrique semblent partager des caractéristiques épidémiologiques différentes de celles des adultes. En effet, la majorité se situent sur l'aspect palmaire de la main et du poignet des patients de moins de dix ans.

OBJECTIF : Déterminer l'épidémiologie, les facteurs étiologiques, la présentation clinique, le traitement et les issues des patients ayant des kystes ganglionnaires ayant consulté au The Hospital for Sick Children de Toronto, en Ontario.

MÉTHODOLOGIE : Les chercheurs ont fouillé les dossiers du département de pathologie de The Hospital for Sick Children afin d'y trouver tous les cas de kystes ganglionnaires opérés entre janvier 2000 et décembre 2008.

RÉSULTATS : Trente-sept patients, dont 23 filles, ont subi un traitement en raison d'un kyste ganglionnaire symptomatique. Les patients avaient un âge moyen de 9,6 ans. Dans 64 \% des cas, un nodule mobile constituait la présentation initiale du ganglion. La douleur était l'indication la plus courante d'excision chirurgicale. Seulement $11,4 \%$ des patients avaient subi un traumatisme préalable. Dans $70 \%$ des cas, le diagnostic était d'ordre clinique. Les principaux foyers d'occurrence étaient l'aspect palmaire du poignet $(25,7 \%)$, l'aspect dorsal du poignet $(22,8 \%)$ et l'aspect palmaire à la base de l'annulaire $(17,1 \%)$. L'excision chirurgicale était le traitement de choix pour $94,2 \%$ des patients ayant des lésions symptomatiques. La période de suivi minimale était de 12 mois. Un seul patient $(2,8 \%)$ a présenté une récurrence dans la série à l'étude.

CONCLUSION : Même s'il est possible que ces observations puissent changer après une période de suivi plus longue, les présentes données fournissent de l'information pour orienter le traitement de ces kystes. Une excision chirurgicale complète représente un traitement très efficace, au très faible taux de récurrence.
G anglion cysts are mucinous tumours that usually arise from underly$\mathbf{J}_{\text {ing joint capsules or tendon sheaths, and are the most common soft }}$ tissue masses of the hand (1). Their pathogenesis remains controversial. The extracapsular part of the dorsal ganglia is well known, but little is known about the intracapsular component and its etiology. While a great deal of information exists for adult hand and wrist ganglia, there is a paucity of data for the pediatric population. Although they commonly occur as benign lesions in adults, ganglia of the hand and wrist are much less common in children. The exact incidence is uncertain, but Nelson et al (1) reported on a series of 543 hand and wrist ganglia. Approximately $10 \%$ occurred in patients younger than 20 years of age, and less than $2 \%$ were in patients younger than 10 years of age. However, the incidence of ganglia in children is probably underestimated because their presence is usually painless and does not interfere with function; therefore, they may not be brought to the attention of a physician.

Pediatric hand and wrist ganglia seem to have different epidemiological characteristics than those of adults - a majority are found on the volar aspect of the hand and wrist in patients younger than 10 years of age (2).
Studies regarding the treatment of hand ganglia in children have generally shown increased rates of recurrence with aspiration or surgery when compared with adults who have undergone similar treatment. Recurrence rates of up to $43 \%$ with various puncture techniques (3), including aspiration, and 35\% following surgical excision have been reported (2). Only a few studies have examined the treatment of pediatric ganglia through observation: MacCollum (4) found a 64\% spontaneous resolution rate in a series that included only dorsal wrist ganglia (gathered from several centres), and Rosson and Walker (5), whose study included patients 15 years of age or younger, reported a $76 \%$ resolution rate in a series that included foot ganglia.

The objectives of the present study were to determine the most common sites of pediatric ganglia occurrence and the most effective method of treatment.

\section{PATIENTS AND METHODS}

The records of the pathology department at The Hospital for Sick Children (Toronto, Ontario) were retrospectively searched for all cases of ganglion cyst surgically treated between January 2000 and

\section{${ }^{1}$ Division of Plastic Surgery, Department of Surgery; ${ }^{2}$ Division of Pathology, Department of Paediatric Laboratory Medicine; ${ }^{3}$ Department of}

Laboratory Medicine and Pathobiology, University of Toronto, The Hospital for Sick Children, Toronto, Ontario

* Both authors contributed equally to the article

Correspondence and reprints: Dr Ronald Melvin Zuker, Division of Plastic Surgery, Department of Surgery, The Hospital for Sick Children, 555 University Avenue, Suite 5416, Toronto, Ontario M5G 1X8. Telephone 416-813-6447, fax 416-813-6147, e-mail Ronald.zuker@sickkids.ca 


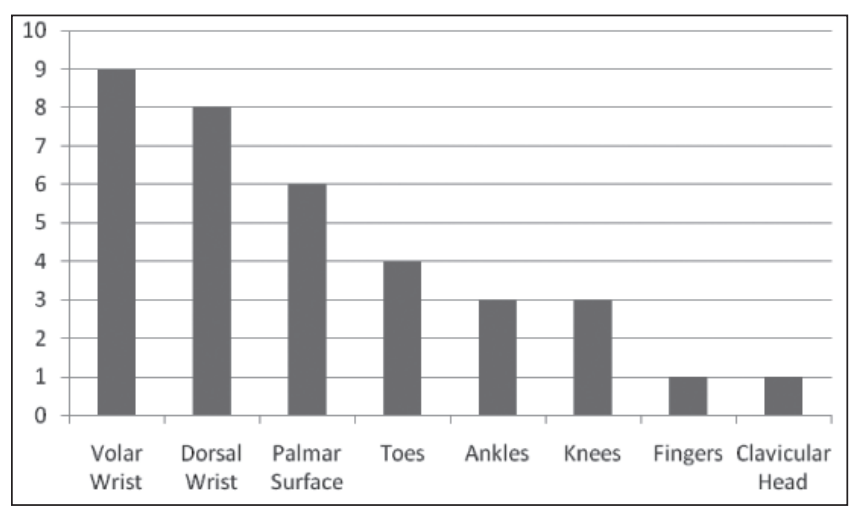

Figure 1) Sites of occurrence of ganglion cysts that were surgically treated in children and adolescents 18 years of age or younger

December 2008. All patients 18 years of age or younger were included. Health charts were then reviewed for epidemiology, etiological factors, history of trauma and indication for surgery. Treatment, follow-up and complications were also recorded.

\section{RESULTS}

Thirty-seven patients underwent treatment for symptomatic ganglion cyst. Surgical excision was the treatment of choice for $94.2 \%$ of patients with symptomatic lesions. The remaining two patients had their cysts aspirated. The following results represent patients who were surgically treated. The mean age of the patients was 9.6 years, ranging from five months to 17 years of age, with 17 of 35 patients 10 years of age or younger. There were 23 females and 12 males. A solid mass was the initial presentation of the ganglion in $43 \%$ of cases, while $57 \%$ presented with a mobile nodule. Pain was the most common indication for surgical removal. Other indications for surgery included swelling, increase of size and limitation of function. Only $11.4 \%$ of the patients reported previous trauma. In $70 \%$ of the cases, the diagnosis was only made clinically. In the remaining cases, $x$-ray or ultrasound were added to the investigation, based on location and symptoms. The right side was affected in $61 \%$ of cases. The most common sites of occurrence were volar wrist $(25.7 \%)$, dorsal wrist $(22.8 \%)$ and the volar aspect of the base of the ring finger (17.1\%) (Figures 1 and 2).

The minimum follow-up period was 12 months. Only one surgically treated patient $(2.8 \%)$ presented with recurrence in the present series. Complications occurred in three $(8.5 \%)$ cases. In two cases, a segment of the radial artery was removed with the volar ganglion cyst. One patient presented with a giant cell reaction (foreign body).

\section{DISCUSSION}

A ganglion is defined as a cystic swelling connected to the joint capsule or tendon sheaths and containing thick gel-like material. Macroscopically, the main cyst, which may be single or multiloculated, usually appears smooth, white and translucent. Microscopically, the wall is composed of compressed collagen fibres and is sparsely lined with flattened cells, without evidence of an epithelial or synovial lining (6). The capsular attachment of the main cyst reveals mucinfilled 'clefts', which have been shown by serial sections to intercommunicate; thereby, forming a tortuous and continuous duct connecting the main cyst with the adjacent underlying joint (6). The content of the cyst is characterized by a highly viscous, clear mucin composed of glucosamine, albumin, globulin and high concentrations of hyaluronic acid (6).

Determining the true incidence of ganglia in children is difficult because they are frequently unreported, often are asymptomatic and usually do not cause functional deficiency. They may also be treated with observation alone by primary care practitioners and not be seen at a tertiary centre. Furthermore, some ganglia resolve spontaneously without medical intervention.

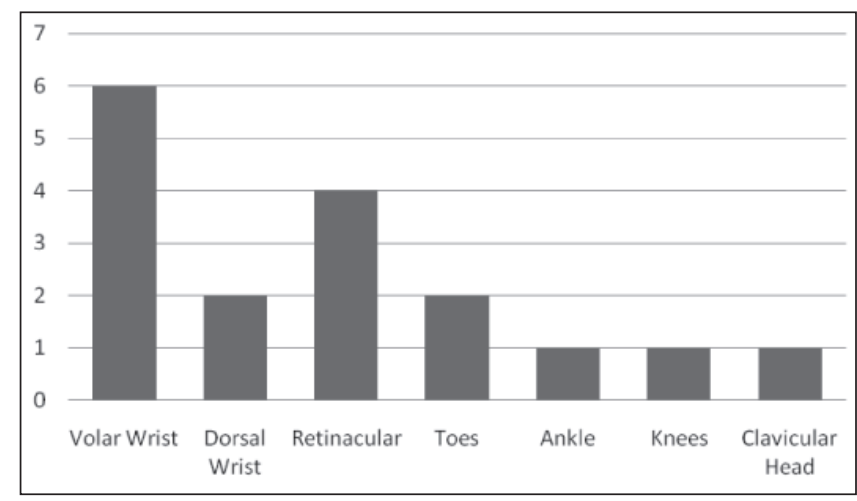

Figure 2) Distribution of ganglion cysts that were surgically treated in children 10 years of age or younger

There have been few reports of hand and wrist ganglia in children. The behaviour of these cysts in young children seems to differ from adults. In adults, dorsal wrist ganglia comprise $60 \%$ to $70 \%$ of all hand and wrist cysts, followed by volar ganglia (18\% to $20 \%)$ and retinacular cysts (10\% to $12 \%$ ) (7). In children, the distribution pattern has not been documented as clearly. Satku and Ganesh (2) reported on a series of surgically treated hand and wrist cysts in children 15 years of age or younger; in older children (older than 10 years of age), the distribution pattern was similar to adults. However, in children younger than 10 years of age, volar cysts $(77 \%)$ were seen more commonly than dorsal cysts $(14 \%)$, and there were few retinacular cysts (9\%). Colon and Upton (8) reported on a series of surgically treated hand masses in children 17 years of age or younger. Their study found slightly more dorsal ganglia (61\%) than volar ganglia (39\%) (in mostly older teenage patients), but the vast majority of retinacular cysts (83\%) occurred in children younger than three years of age. Coffey et al (9) reported on 1629 patients treated for hand and wrist ganglia during a three-year period. Of these, 48 patients were children 12 years of age or younger (31 girls and 17 boys; ratio of 1.8:1), with an average age at presentation of 7.2 years. There were 22 (45\%) dorsal and 27 (55\%) volar hand and wrist ganglia. In the present study, we found slightly more volar (25.7\%) than dorsal ganglia. However, this may be because volar cysts are more symptomatic than dorsal cyst, and more often involve surgical treatment. In our children 10 years of age or younger, $35 \%$ had volar ganglia. The majority of retinacular cysts $(67 \%)$ occurred in children 10 years of age or younger.

A female prevalence has been noted in many studies of adult ganglia: women are up to three times more likely to be affected than men (10). A similar sex bias has also been seen in the pediatric population: the proportion of affected females to males has been reported to range from 1.6:1 (3) to 4:1 (2). Wang and Hutchinson (11) also reported a female to male ratio of 4.7:1. The 1.9:1 ratio found in our study also supports these findings.

Although there is no general consensus regarding the best treatment for pediatric ganglia, most prefer observation and splinting, with Wang and Hutchinson (11) reporting 79\% resolution. Treatment of ganglia in adults often includes aspiration of the cyst. Cure rates after aspiration reported for dorsal cysts range from $13 \%$ (12) to $85 \%$ (13). Aspiration has not been generally recommended in treating volar cysts because of the potential for neurovascular injury and because the recurrence rate of volar ganglia after aspiration is higher than that of dorsal cysts ( $57 \%$ to $83 \%$ ) (12). Aspiration and other similar cyst puncture treatments have also been performed in children, with mostly unfavourable results. MacKinnon and Azmy (3) reviewed 32 patients younger than 14 years of age with wrist ganglia treated using aspiration, puncture or indwelling suture, and found a recurrence rate of $43 \%$. Colon and Upton (8) reported only a $20 \%$ success rate with aspiration of dorsal and volar ganglia, and a less than $20 \%$ success rate with aspiration of retinacular cysts. Aspiration was performed in only $6 \%$ of our patients. We found it 
very difficult to aspirate ganglia in younger children in the office. Surgical excision was the treatment of choice in $94 \%$ of our symptomatic patients.

Surgical excision of wrist ganglia has been reported to have the best success rates in terms of recurrence; in 1976, Angelides and Wallace (14) reported a 99\% success rate. Complications of surgery include wound-healing complications, such as infection, neuroma or keloid formation, and the presence of a scar. Other reported complications include scapholunate dissociation, joint stiffness, damage to the terminal branches of the posterior interosseous nerve, and decreased grip strength along with the risks associated with the use of general anaesthesia and upper limb tourniquet (15). We had a complication rate of $8.5 \%$. In two cases, a segment of the radial artery was removed with the volar ganglion cyst, and one patient presented with a giant cell reaction (foreign body).

The reported recurrence rate of ganglia after surgery is quite high. Barnes et al (16) stated that in most reviews, the recurrence rate was approximately 40\%. Zachariae and Vibe-Hansen (17) reported a recurrence rate of $34 \%$ in a series of 347 patients who were operated on in a well-established hand clinic. These recurrence rates were comparable with other modes of therapy such as crushing, aspiration and injection (16). Our minimum follow-up period was 12 months. There was one recurrence in the present series $(2.8 \%)$ in patients undergoing surgical treatment.

Although it is possible that these findings will change with longer follow-up, our data provide useful information to help guide treatment of these symptomatic cysts in children. In the case of an unresolved cyst, the risks and benefits of continued observation versus surgery, including recurrence rates and potential complications, should be discussed with the patients or their families.

CONFLICTS OF INTEREST: The authors have no conflicts of interest to declare.

\section{REFERENCES}

1. Nelson CL, Sawmiller S, Phalen GS. Ganglions of the wrist and hand. J Bone Joint Surg Am 1972;54:1459-64.

2. Satku K, Ganesh B. Ganglia in children. J Pediatr Orthop 1985;5:13-5.

3. MacKinnon AE, Azmy A. Active treatment of ganglia in children. Postgrad Med J 1977;53:378-81.

4. MacCollum MS. Dorsal wrist ganglions in children: Clinical notes. J Hand Surg 1977;2:325.

5. Rosson JW, Walker G. The natural history of ganglia in children. J Bone Joint Surg 1989;71B:707-8.

6. Singhal R, Angmo N, Gupta S, Kumar V, Mehtani A. Ganglion cysts of the wrist: A prospective study of a simple outpatient management. Acta Orthop Belg 2005;71:528-34.

7. Angelides AC. Ganglions of the hand and wrist. In: Green DP, Hotchkiss RN, Pederson WC, eds. Operative Hand Surgery, 4th edn. New York: Churchill Livingstone, 1999;2:2171-83.

8. Colon F, Upton J. Pediatric hand tumors. Hand Clin 1995;11:223-43.

9. Coffey MJ, Rahman MF, Thirkannad SM. Pediatric ganglion cysts of the hand and wrist: An epidemiologic analysis. Hand 2008:359-62.

10. Thornberg LE. Ganglions of the wrist and hand. J Am Acad Orthop Surg 1999; 7:231-8.

11. Wang A, Hutchinson DT. Longitudinal observation of pediatric hand and wrist ganglia. J Hand Surg 2001;26A:599-602.

12. Richman JA, Gelberman RH, Engber WD, et al. Ganglions of the wrist and digits: Results of treatment by aspiration and cyst wall puncture. J Hand Surg 1987;12A:1041-3.

13. Zubowicz VN, Ishii CH. Management of ganglion cysts of the hand by simple aspiration. J Hand Surg 1987;12A:618-20.

14. Angelides AC, Wallace PF. The dorsal ganglion of the wrist: Its pathogenesis, gross and microscopic anatomy and surgical treatment. J Hand Surg 1976;1:228-35.

15. Paul AS, Sochart DH. Improving the results of ganglion aspiration by the use of hyaluronidase. J Hand Surg 1997;22B:219-21.

16. Barnes WE, Larsen RD, Posch JL. Review of ganglia of the hand and wrist with analysis of surgical treatment. Plastic Reconstr Surg 1964:34:570-8.

17. Zachariae L, Vibe-Hansen H. Ganglia. Recurrence rate elucidated by a follow up of 347 operated cases. Acta Chir Scand 1973;139:625-8. 